\title{
Primary liposarcoma of the heart
}

\author{
Christina Maria Steger \\ Department of Pathology, Innsbruck Medical University, Innsbruck, Austria
}

Correspondence to Dr Christina Maria Steger, christina.m.steger@i-med.ac.at

\section{Summary}

The author reports a case of a 64-year-old man, who presented with a 4-week history of dyspnoea and dizziness suffering from a large mass in the pericardium. CT of the chest showed a lobulated mass in the pericardial sac located between the pulmonary veins and the ascending aorta reaching the superior vena cava. The tumour was completely resected and histopathological analysis revealed the tumour to be a welldifferentiated lipoma-like and focal sclerosing liposarcoma, which was composed predominantly of adipocytes with hyperchromatic nuclei and eosinophilic-to-vacuolated cytoplasm disrupted by fibrous septa. Two years after initial tumour diagnosis the patient is still alive without signs of tumour recurrence.

\section{BACKGROUND}

Primary liposarcoma of the mediastinum is extremely rare, representing $<1 \%$ of mediastinal tumours with $<150$ cases reported in the literature. Differentiation from lipomas can be difficult and is based on histological examination of excised specimens. Mediastinal liposarcoma develops more commonly in the posterior mediastinum and usually occurs in adults, with a peak incidence in individuals aged 40-60 years. ${ }^{1}$ Men are affected twice as often as women. ${ }^{2}$
Liposarcoma, first described by Virchow in $1857,{ }^{3}$ normally occurs in the deep soft tissue of extremities and in the retroperitoneum. Other unusual locations may include the peritoneal cavity, spermatic cord, axilla, vulva, breast and the heart. It is the most common soft tissue sarcoma and accounts for $20 \%$ of all mesenchymal tumours.

According to the experience of the Armed Forces Institute of Pathology, in collaboration with the Mayo Clinic, 75\% of the cases of liposarcoma develop in deep muscle tissues

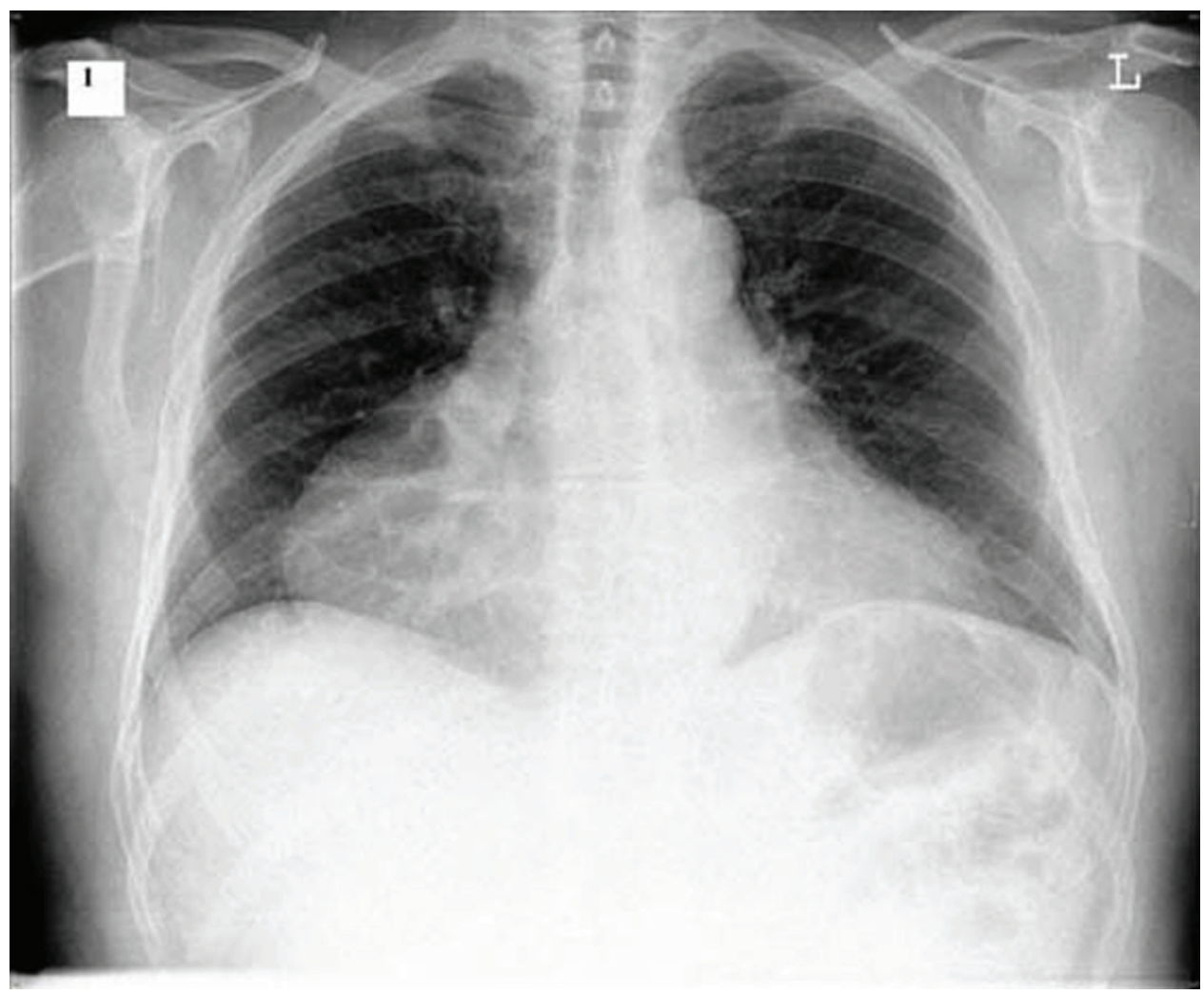

Figure 1 Chest x-ray with the enlarged heart silhouette. 


\section{BMJ Case Reports}

of the extremities, $20 \%$ develop in the retroperitoneum and the remaining develop at other sites. ${ }^{4}$

The cell of origin of liposarcomas is presumed to be an undifferentiated, pluripotent mesenchymal cell.

A number of cytogenetic correlations have been made with liposarcomas. Well-differentiated liposarcomas have been found to be associated with abnormalities derived from the q13-15 region of chromosome $12 .{ }^{5}$ However, the molecular basis for wide range of differentiation of these tumours is unknown. ${ }^{67}$

Diagnosis and classification of liposarcoma is based on histopathological criteria established by the WHO. Liposarcoma can be classified into four distinct histological types: well-differentiated (or atypical lipoma), dedifferentiated, myxoid/round cell and pleomorphic (table 1). Well-differentiated liposarcoma accounts for $40-45 \%$ of all liposarcomas and the lipoma-like form is by far the most common of its variants.

\section{CASE PRESENTATION}

In April 2009, a 64-year-old male presented with a 4-week history of exertional dyspnoea and dizziness.

Chest x-ray demonstrated a markedly enlarged heart silhouette (figure 1). Echocardiography revealed normalsized ventricles and a normal global contractile function. Chest CT suspected a lipoma or liposarcoma with a maximum diameter of $14 \mathrm{~cm}$. The mass was located between the ascendic aorta and the truncus pulmonalis, reached the superior vena cava and lead to compression of the right atrium and the superior vena cava (figures 2 and 3). Radiologically, no evidence of metastases or further tumour formations were apparent. Laboratory tests showed no signs of inflammation (erythrocyte sedimentation rate,

Table 1 Liposarcoma subtypes

\begin{tabular}{ll}
\hline Well-differentiated & Includes atypical lipoma \\
& Most common subtype (50\% of liposarcomas) \\
& Low grade (does not metastasise, but may recur locally) \\
& Risk of dedifferentiation \\
Myxoid & Intermediate grade \\
& Includes round-cell variant as its high-grade counterpart \\
& Most common type in pediatric age group \\
& Metastatic risk especially in round-cell variant \\
Pleomorphic & Rarest type (5-10\% of liposarcomas) \\
& High grade \\
& May mimic MFH or even carcinoma or melanoma \\
& High risk of local recurrence and metastasis \\
Dedifferentiated & High-grade sarcoma arising in association with well- \\
& differentiated liposarcoma (MFH, fibrosarcoma) \\
& Most common with retroperitoneal lesions \\
& Risk of metastasis
\end{tabular}

MFH, malignant fibrous histiocytoma.

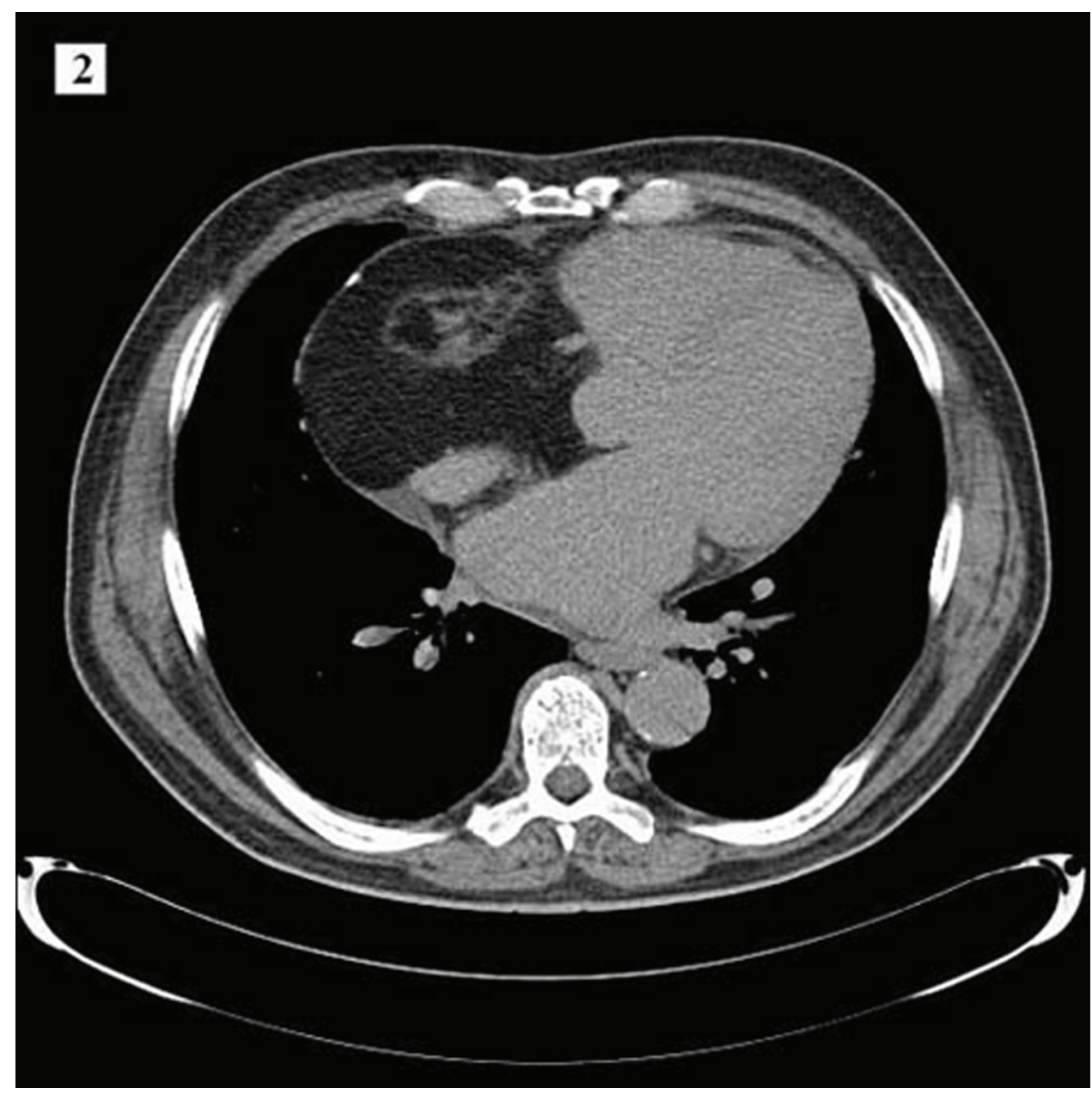

Figure 2 Chest CT showing the lipomatous tumour mass. 


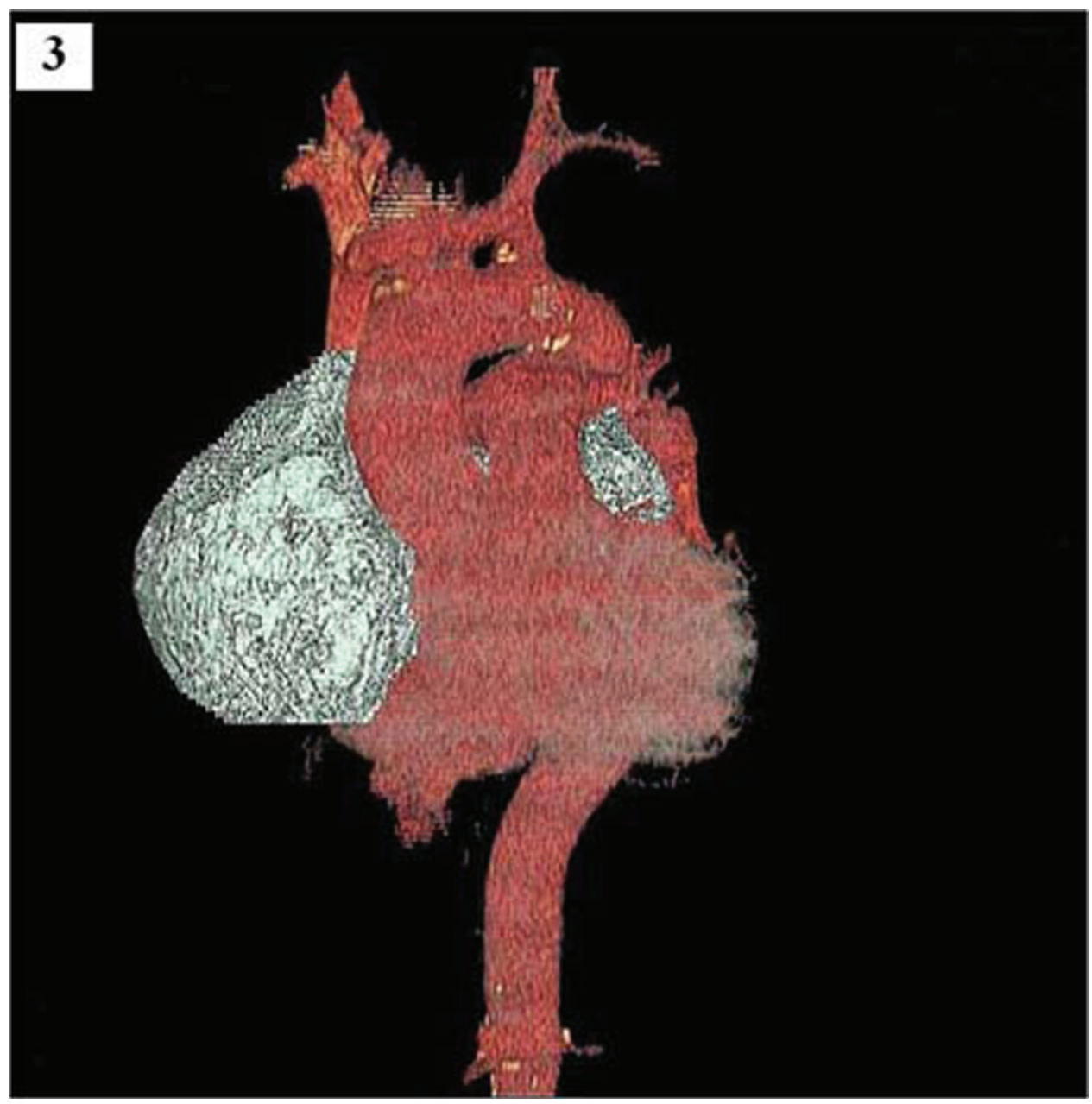

Figure 33 D reconstruction of the heart with the liposarcoma between truncus pulmonalis and ascendic aorta.

fibrinogen, $\mathrm{C}$ reactive protein, lactate dehydrogenase were all within the range).

Respiratory function tests and arterial blood gas analyses were within normal limits. Two weeks later, tumorectomy was performed with the support of cardiopulmonary bypass under cardiac arrest. After median sternotomy and incision of the pericardium the lipomatous tumour mass was encountered. The tumour was pedunculated with origin from the right atrium and was radiologically suspected behind the ascendic aorta and truncus pulmonalis reaching the left auricle of the heart. Mobilisation of the tumour mass was difficult due to adhesions between the tumour and the pericardium. Surgically, complete resection was obtained. The pericardium was not resected.

The early postoperative course was uneventful and the patient was discharged 6 days after open heart surgery.

\section{INVESTIGATIONS}

Grossly, the lobulated tumour mass measured $14 \times 10 \times 8$ $\mathrm{cm}$ in size, weighted $712 \mathrm{~g}$, and showed haemorrhage on the surface. On sectioning, it was yellow, soft and smooth with a light-coloured glossy nodule $(5 \times 4 \mathrm{~cm})$ inside. Histologically, the tumour was characterised by a variation in size of adipocytes, some of which showing round hyperchromatic nuclei, often prominent nucleoli, and variably eosinophilic-to-vacuolated cytoplasm. Within the tumour formations fibrous septa and focal chronic inflammatory infiltrates, mainly consisting of lymphocytes, were found (figure 4). No lymph vessel or vessel infiltration, no significant necrosis or mitosis was present. The resection margins were free of tumour formation.

Finally, the diagnosis of a well-differentiated lipoma-like and focal sclerosing liposarcoma was made.

\section{DIFFERENTIAL DIAGNOSIS}

The differential diagnosis includes

- Mediastinal lipoma

- Thymolipoma

- Angiolipoma

- Fibromyxolipoma

- Teratoma.

\section{OUTCOME AND FOLLOW-UP}

Two years after surgery the patient is alive without any signs of tumour recurrence or metastatic disease, although a subsequent irradiation or chemotherapy was not performed.

\section{DISCUSSION}

Although liposarcoma is the most common tumour of mesenchymal origin in adults, a mediastinal location is extremely rare. ${ }^{4}$ 8-14 Primary mediastinal liposarcoma 


\section{BMJ Case Reports}
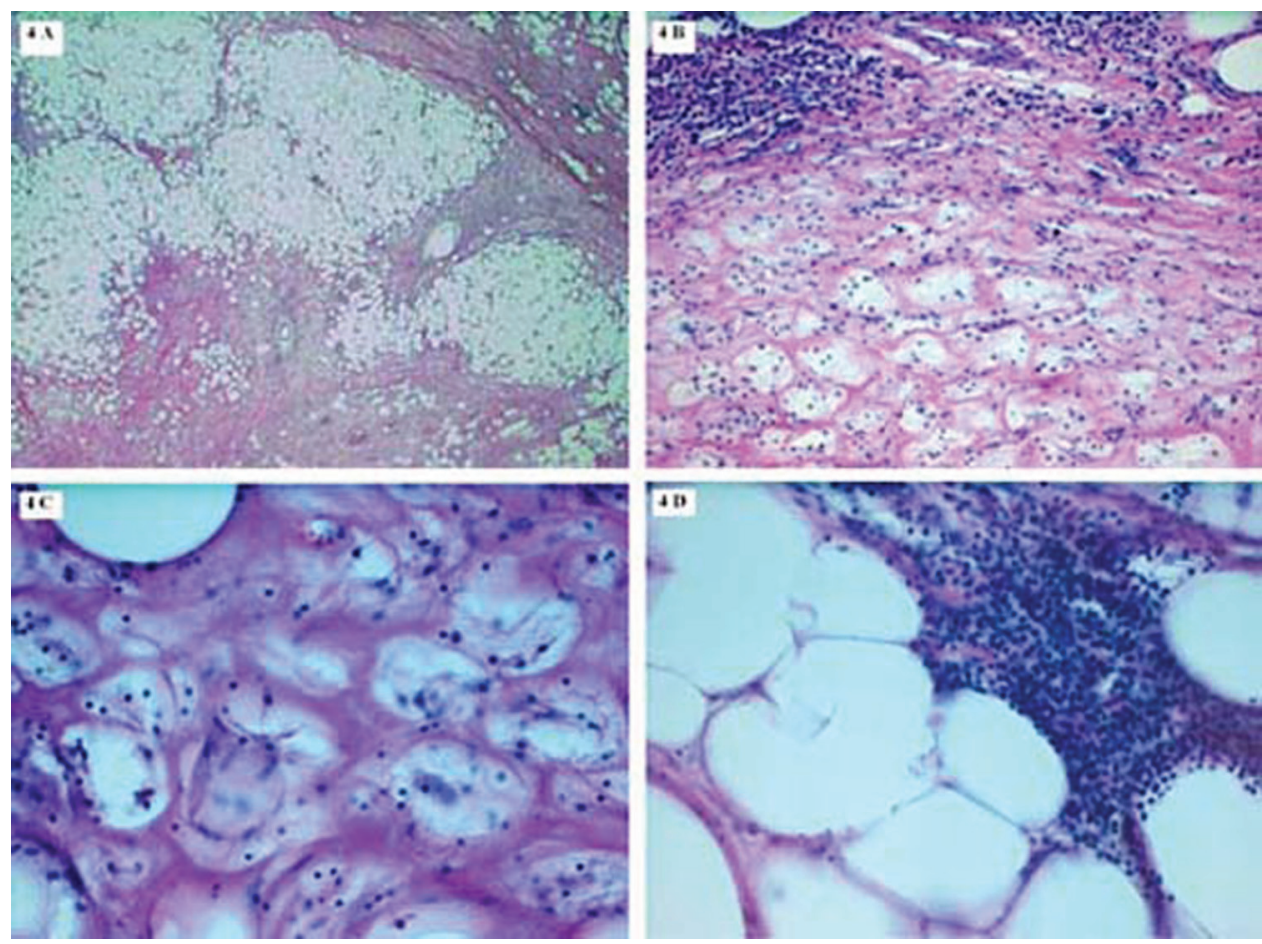

Figure 4 Histological examination revealed adipocytes with eosinophilic-to-vacuolated cytoplasm, fibrous septa and lymphocytic infiltration (H\&E staining, $(A)$ - original magnification $\times 4$, (B) - original magnification $\times 10,(C, D)$ - original magnification $\times 40$ ).

accounts for only $0.13-0.75 \%$ of all mediastinal tumours ${ }^{15}$ and constitutes about $13 \%$ of all cardiac sarcomas. ${ }^{6} 7$ 16-17 By definition, pericardial liposarcomas must be confined to the pericardium, at the time of presentation or the bulk of the tumour must be within the pericardial cavity. In every case exclusion of an occult primary is essential as secondary tumours are 100-1000 times more common. ${ }^{67}$

About $20-24 \%$ of the cardiac sarcomas remain unclassified either due to inadequate sampling of those tumours which demonstrate focal areas of differentiation or due to lack of adequate material for complete immunohistochemical and ultrastructural analysis.

Needle biopsies, either fine needle or core, are often inadequate for accurate diagnosis of lipomatous tumours. Low-grade liposarcomas are difficult to distinguish from benign lipomas on needle biopsy and larger tissue specimens, from incisional or excisional biopsies, are usually required.

Depending on their size and location within the heart, liposarcomas may present with chest pain, symptoms of right- or left-sided heart failure, pericarditis with or without cardiac tamponade, palpitation, rhythm disturbances, syncope, angina, cough and constitutional symptoms like fever and weight loss. ${ }^{18-20}$ Dyspnoea is the most common symptom. In cases where the tumour does not interfere with cardiac function, patients may be entirely asymptomatic. ${ }^{2} 21$

Liposarcomas can invade adjacent organs, so they are more likely to be symptomatic than benign lipomas, which simply compress adjacent structures. Liposarcomas have a predilection for local recurrence but do not generally metastasise.

The role of adjuvant chemotherapy remains controversial, ${ }^{22}$ and is best addressed on a case-by-case basis.
In this case complete surgical resection was possible, so a subsequent chemotherapy was not performed.

In general, the treatment of choice is surgery, and complete resection of the tumour is recommended whenever possible. ${ }^{8} 2324$ According to the literature, aggressive surgical intervention seems to favour the quality of life of patients and prolong survival, being considered the most effective treatment. ${ }^{14}$

The prognosis depends on the histological subtype and on surgical resection with wide margins of safety. ${ }^{24} 25$ Recurrence is seen in approximately $40 \%$ of the cases and has been reported at up to 14 years after the initial surgical procedure. $^{25}$

Behaviour of a specific tumour is ultimately dependent on its histological subtype. When treated with surgery and perioperative radiation therapy, well-differentiated liposarcomas exhibit a $<10 \%$ local recurrence rate and a virtually $0 \%$ rate of metastasis. ${ }^{26}$ In contrast, pleomorphic liposarcomas recur in about $1 / 3$ of cases and spread in about $40 \%$. Five and 10-year survival rates for patients with liposarcomas have been reported as $100 \%$ and $87 \%$ for well-differentiated, $88 \%$ and $76 \%$ for myxoid variants and $56 \%$ and $39 \%$ in the pleomorphic subtype. ${ }^{26} 27$ Features associated with longer survival include (1) left-sided tumour, (2) complete tumour resection, (3) postoperative adjuvant therapy and (4) tumours with less than 10 mitoses/HPF and absent necrosis. 61617

Once the tumour has been excised and adjuvant therapy completed, continued surveillance is required to promptly detect any evidence of local recurrence or distant metastasis. This typically involves careful physical examination, chest $\mathrm{x}$-rays and serial imaging of the chest and abdomen (usually CT). 
In conclusion, surgical resection is the treatment of choice, and depending on the histological subtype an additional irradiation or chemotherapy may be necessary to avoid tumour recurrence. However, long-term follow-up evaluation is indicated in all cases of liposarcomas of the heart.

\section{Learning points}

- Primary mediastinal liposarcomas are extremely rare. They comprise less than $1 \%$ of all mediastinal tumours.

- Depending on the tumour size, liposarcomas can be asymptomatic or symptomatic. Symptoms include dyspnoea, chest pain, palpitation, rhythm disturbances, syncope, angina, cough and constitutional symptoms like fever and weight loss.

- Histological distinction between liposarcomas and lipomas can be very difficult and adequate sampling of tumour specimens is required to confirm the suspected diagnosis.

- Needle biopsies are often inadequate for accurate diagnosis of lipomatous tumours.

- For successful treatment complete surgical resection is required, sometimes supplemented by subsequent radiation or chemotherapy.

\section{Competing interests None}

Patient consent Obtained.

\section{REFERENCES}

1. Ohta Y, Murata T, Tamura M, et al. Surgical resection of recurrent bilateral mediastinal liposarcoma through the clamshell approach. Ann Thorac Surg 2004;77:1837-9.

2. Matsakas EP, Lazaros GA, Panou FK, et al. Primary pericardial fibrosarcoma presenting as "near" cardiac tamponade. Clin Cardiol 2002;25:83-5.

3. Virchow R. Ein Fall von bösartigen zum Theil in der Form des Neurons auftretenden Fettgeschwulsten. Arch A Pathol Anat Phys 1857:11:281-8.

4. Weiss SW. Liposarcoma. In: Weiss SW, Goldblum JR, eds. Enzinger and Weiss's Soft Tissue Tumors. Fourth edition. St Louis: Mosby 2001:641-94.

5. Rubin BP, Fletcher CD. The cytogenetics of lipomatous tumours. Histopathology 1997;30:507-11
6. Burke A, Virmani R, eds. Primary cardiac sarcomas. In: Atlas of Tumor Pathology: Tumors of the Heart and Great vessels. First edition. Washington, DC: Armed Force Institute of Pathology 1996: 127-170.

7. Sarjeant JM, Butany J, Cusimano RJ. Cancer of the heart: epidemiology and management of primary tumors and metastases. Am J Cardiovasc Drugs 2003;3:407-21

8. Kiyama H, Tanabe S, Nagasawa S, et al. [A case of primary anterior mediastinal liposarcoma with a heterotopic mass in the pericardium of the same histology]. Nippon Kyobu Geka Gakkai Zasshi 1996;44:2191-5.

9. Mase T, Kawawaki N, Narumiya C, et al. Primary liposarcoma of the mediastinum. Jpn J Thorac Cardiovasc Surg 2002;50:252-5.

10. Wick MR. The mediastinum. In: Sternberg SS, Antonioli DA, eds. Diagnostic Surgical Pathology. Philadelphia, PA: Lippincott Williams and Wilkins 1999:1147-208.

11. Okumori M, Mabuchi M, Nakagawa M. Malignant thymoma associated with liposarcoma of the mediastinum-a case report. Jpn J Surg 1983;13:512-18.

12. Yonehara S, Kou E, Hasegawa K, et al. [Liposarcoma of the mediastinum-a case report]. Gan No Rinsho 1986;32:810-14.

13. Rivo JE, Cañizares MA, García-Fontán E, et al. [Liposarcomas of the mediastinum in atypical locations: report of two cases]. Cir Esp 2005;77:99-101.

14. Teschner $\mathbf{M}$, Lüllig $\mathrm{H}$. [Diagnosis and treatment of primary mediastinal liposarcoma]. Pneumologie 2003;57:22-6.

15. Tanaka F, Kitano M, Tatsumi A, et al. [A case of mediastinal liposarcoma]. Nippon Kyobu Geka Gakkai Zasshi 1992;40:1125-30.

16. Anand AK, Khanna A, Sinha SK, et al. Pericardial synovial sarcoma. Clin Oncol (R Coll Radiol) 2003:15:186-8.

17. Burke AP, Cowan D, Virmani R. Primary sarcomas of the heart. Cancer 1992;69:387-95

18. Lacey CJ, Petch MC. Primary liposarcoma of the pericardium. Thorax 1979;34:120-2

19. Can C, Arpaci F, Celasun B, et al. Primary pericardial liposarcoma presenting with cardiac tamponade and multiple organ metastases. Chest 1993:103:328.

20. Kindl TF, Hassan AM, Booth RL Jr, et al. A primary high-grade pleomorphic pericardial liposarcoma presenting as syncope and angina. Anesth Analg 2006;102:1363-4.

21. Lorell BH. Pericardial diseases. In: Braunwald E, ed. Heart Disease. Fifth edition. Philadelphia, PA:WB Saunders Co 1997:1478-534.

22. Meyer $\mathbf{M}$, Holzhausen $\mathrm{HJ}$, Neef $\mathrm{H}$, et al. [Primary liposarcomas of the mediastinum]. Langenbecks Arch Chir Suppl Kongressbd 1998;115:369-73.

23. Doğan R, Ayrancio lu K, Aksu 0. Primary mediastinal liposarcoma. A report of a case and review of the literature. Eur J Cardiothorac Surg 1989;3:367-70.

24. Farah M, Abou-Sleiman P, Bahous J. Primary mediastinal liposarcoma: a case report and review of the literature. J Med Liban 2001:49:165-9.

25. Bonnette $\mathbf{P}$, Jouan J, Colchen A, et al. [Myxoid liposarcoma of the mediastinum]. Rev Mal Respir 2000;17:109-11.

26. Zagars GK, Goswitz MS, Pollack A. Liposarcoma: outcome and prognostic factors following conservation surgery and radiation therapy. Int J Radiat Oncol Biol Phys 1996:36:311-19.

27. Chang HR, Hajdu SI, Collin C, et al. The prognostic value of histologic subtypes in primary extremity liposarcoma. Cancer 1989;64:1514-20.

This pdf has been created automatically from the final edited text and images.

Copyright 2011 BMJ Publishing Group. All rights reserved. For permission to reuse any of this content visit

http://group.bmj.com/group/rights-licensing/permissions.

BMJ Case Report Fellows may re-use this article for personal use and teaching without any further permission.

Please cite this article as follows (you will need to access the article online to obtain the date of publication).

Steger CM. Primary liposarcoma of the heart. BMJ Case Reports 2011;10.1136/bcr.03.2011.4013, date of publication

Become a Fellow of BMJ Case Reports today and you can

- Submit as many cases as you like

- Enjoy fast sympathetic peer review and rapid publication of accepted articles

- Access all the published articles

- Re-use any of the published material for personal use and teaching without further permission

For information on Institutional Fellowships contact consortiasales@bmjgroup.com

Visit casereports.bmj.com for more articles like this and to become a Fellow 